\title{
Epstein-Barr-Virus-Infected CD15 (Lewis X)-Positive Hodgkin-Lymphoma- Like B Cells in Patients with Rheumatoid Arthritis
}

\author{
Hirotake Inomata $^{\S, 1}$, Masami Takei ${ }^{*} \S, 1$, Hiroyuki Nakamura ${ }^{2}$, Shigeyoshi Fujiwara ${ }^{2}$, Hidetaka Shiraiwa ${ }^{1}$, \\ Noboru Kitamura ${ }^{1}$, Shunsei Hirohata ${ }^{3}$, Hiroyuki Masuda ${ }^{1,4}$, Jin Takeuchi ${ }^{1}$ and Shigemasa Sawada ${ }^{*}$, \\ ${ }^{I}$ Division of Hematology and Rheumatology, Department of Medicine, Nihon University School of Medicine, Tokyo, Japan \\ ${ }^{2}$ Department of Infectious Diseases, National Research Institute for Child Health and Development, Tokyo, Japan \\ ${ }^{3}$ Department of Rheumatology and Infectious Diseases, Kitasato University School of Medicine, Kanagawa, Japan \\ ${ }^{4}$ Intellim Corporation, Tokyo, Japan
}

\begin{abstract}
Patients with rheumatoid arthritis (RA), especially those who are treated with methotrexate (MTX), might have an increased risk of Hodgkin lymphoma (HL), a malignancy that is associated with Epstein-Barr virus (EBV). Here we describe a monoclonal EBV-infected B-lymphoblastoid cell line (LCL) called TKS-1 that was established from cells that spontaneously converted from an MTX-treated RA patient. TKS-1 has properties similar to HL cells and it is distinctly different from control LCLs established from normal individuals. TKS-1 cells express the HL -associated surface markers CD15 and CD30 (Takei et al. 1989). Like Hodgkin Reed-Sternberg (H-RS) cells of EBV-positive HL, TKS-1 cells express EBNA1 mRNA transcribed from the Qp promoter of the virus, whereas control LCLs use the Cp or Wp promoter to transcribe mRNA. TKS-1 cells can proliferate in an anchorage-independent manner and possess a cloning efficiency comparable to that of the Burkitt lymphoma (BL) line Raji. In addition, two EBV-positive LCLs established by cocultivated CD34+ cells isolated from the bone marrow of patients with RA and peripheral blood B lymphocytes from a healthy EBV-seronegative individual also expressed CD15. These results indicate that EBV-infected B-lymphoblastoid cells from patients with RA tend to acquire properties similar to HL cells.
\end{abstract}

\section{INTRODUCTION}

The relationship between rheumatoid arthritis (RA) and Epstein-Barr virus (EBV)-associated lymphoproliferative disorders including Hodgkin lymphoma (HL) is inconclusive and controversial. We previously established a monoclonal EBV-infected B-lymphoblastoid cell line (LCL) called TKS1 [1]. The disease-modifying anti-rheumatic drug (DMARD) methotrexate (MTX) sometimes causes malignancies of this type [2] and in some patients these EBV-associated lymphomas completely regress when MTX therapy is reduced or discontinued [3]. Mariette et al. have performed a nationwide prospective study that suggests an increased risk for HL [4], but not for non-Hodgkin lymphoma (NHL) in patients with RA who are treated with MTX. However, Baecklund et al. demonstrated on 378 consecutive Swedish patients with RA that the most common DMARDs including MTX are not in themselves a risk factor for RA-associated lymphomas, nor does treatment further increase the risk associated with high inflammatory activity [5]. Although most "excess" lymphomas in RA are of the aggressive diffuse large B cell lymphoma type, the presence of EBV in RA-associated lymphomas is low.

*Address correspondence to these authors at the Division of Hematology and Rheumatology, Department of Medicine, Nihon University School of Medicine, 30-1 Oyaguchi Itabashi-ku, Tokyo, Japan; Tel: +81-3-3972-8111; Fax: +81-3-3972-2893;

E-mails: numtakei@med.nihon-u.ac.jp,sswd98@med.nihon-u.ac.jp

${ }^{\S}$ These authors contributed equally to this work
The CD15 antigen is a marker of granulocytes, macrophages and activated T cells and $37-100 \%$ of HodgkinReed Sternberg (H-RS) cells and the malignant cells of HL are positive for this antigen [6]. The CD15 antigen binds to the adhesion molecule, P-selectin [7] and the anti-CD15 antibody recognizes the sugar moiety lacto-N-fucopentaoseIII (LNF-III) [8, 9] or Lewis $\mathrm{X}$ antigen. P-selectin is an external membrane protein on activated platelets that has also been referred to as platelet activation-dependent granule-external membrane protein (PADGEM), granule membrane protein 140 (GMP-140) or CD62 [10, 11].

An association between RA and EBV is also recognized [12-14]. Direct evidence includes a demonstration of EBVencoded small nuclear RNA (EBER-1) and latent membrane protein (LMP)-1 in the synovial cells of RA [15]. Other studies subsequently confirmed this finding [16-20] except for one that did not find evidence of EBV infection in a synovial lesion of RA [14]. Another notable finding associating EBV with RA is that the expression of signalling lymphocytic-activation molecule associated protein (SAP) transcripts is decreased in $\mathrm{T}$ cells from RA patients [21]. This protein plays an essential role in cytotoxic $\mathrm{T}$ and $\mathrm{NK}$ cells that are involved in the immune response to EBV.

To gain insight into the relationships between each of EBV and RA with HL, we characterized the surface phenotypes, EBV gene expression, and malignant potential of EBV-infected lymphoblastoid cell line (LCL) (TKS-1) established from a patient with RA and found that these cells tended to acquire properties similar to those of HL cells. 


\section{MATERIALS AND METHODS}

\section{Cells}

Peripheral blood mononuclear cells from a patient with RA were stimulated with phorbol myristate acetate (PMA) to establish the $\mathrm{EBV}^{+} \mathrm{B}$ lymphoblastoid cell line TKS [1]. Two subclones (type $1 \& 2$ ) of TKS were isolated by repeated limiting dilution in 96-well micro-culture plates. The phenotypes of these clones were $\mathrm{CD} 15^{+} \mathrm{CD} 30^{+} \mathrm{CD} 19^{+}$ $\mathrm{CD} 20^{+}$(type 1 ) and $\mathrm{CD} 15^{+} \mathrm{CD} 30^{+} \mathrm{CD} 19^{-} \mathrm{CD} 20^{+}$(type 2 ) (Fig. 1). The type 1 subclone of TKS cells (TKS-1) reacted with the following antibodies against surface antigens: Ig light chain kappa, HLA-DR, Leu 10, Leu 12 (CD19), Leu 16 (CD20), Leu M1 (CD15), and Ki-1 (CD30). These cells did not react against the antibodies OKM1 (CD11b), Leu M2, Leu M3 (CD14), Leu M4, or to T cell surface or natural killer cell antigens. TKS-1 cells were peroxidase-negative, slightly positive for non-specific esterase that was not inhibited by $\mathrm{NaF}$, had monoclonal immunoglobulin light chain gene rearrangement and expressed EBNA-1 mRNA [1]. The RABM/EBV ${ }^{+} 1-3$ cell lines are $\mathrm{EBV}^{+}$LCLs that were established by co-cultivating bone marrow $\mathrm{CD}^{+} 4^{+}$cells obtained from RA patients with peripheral $\mathrm{B}$ cells isolated from an EBV-seronegative healthy individual [22]. Akata and Raji are $\mathrm{EBV}^{+}$Burkitt lymphoma (BL) cell lines, BJAB is an EBV-negative B lymphoma line [23]. GL-1 and CBL2 are $\mathrm{EBV}^{+} \mathrm{LCL}$ established by infecting peripheral $\mathrm{B}$ cells from a healthy donor with EBV, and DI-1 and DI-5 are LCLs that were spontaneously established from an EBV seropositive donor. Table 1 summarizes the cell lines used in this study. All cell lines were cultured in RPMI 1640 supplemented with $10 \%$ heat-inactivated fetal calf serum (FCS) and antibiotics.

Table 1. Cell Lines Used in this Study and Positive Ratio of CD15/CD19

\begin{tabular}{|c|c|c|}
\hline Cell Line & Origin of Cell Lines & CD15/CD19 \\
\hline TKS & $\begin{array}{l}\text { Mononuclear cells from peripheral blood of } \\
\text { RA patient were cultured with PMA for } 4 \\
\text { weeks and then clusters formed }\end{array}$ & + \\
\hline TKS-1 & $\begin{array}{l}\text { TKS as described above, subclone. Two } \\
\text { limiting dilutions performed }\end{array}$ & $+++(98 \%)$ \\
\hline $\begin{array}{c}\mathrm{RABM} / \mathrm{EBV}+1 \\
2 \\
3\end{array}$ & $\begin{array}{l}\text { EBV positive B cell lines obtained by co- } \\
\text { cultured RA bone marrow CD } 34^{+} \text {cells and } \\
\text { normal EBV negative peripheral B cells }\end{array}$ & $\begin{array}{c}- \\
+++(83) \\
+++(86)\end{array}$ \\
\hline B95-8 LCL & $\begin{array}{l}\text { Normal B cell line transformed with B95-8 } \\
\text { supernatant. Normal donor is same as } \\
\text { RABM/EBV1-3 described above. }\end{array}$ & \pm \\
\hline$\underset{\text { Raji }}{\text { Akata, BJAB, }}$ & $\begin{array}{l}\text { Burkitt lymphoma cell lines GL-1 and CBL2 } \\
\text { are } \mathrm{EBV}^{+} \mathrm{LCL}\end{array}$ & - \\
\hline $\begin{array}{l}\text { GL-1 and } \\
\text { CBL2, DI-1, } \\
\text { DI-5 }\end{array}$ & $\begin{array}{l}\text { Established by infecting peripheral B cells } \\
\text { from healthy donor with EBV. DI-1 and DI- } \\
5 \text { are LCLs spontaneously established from } \\
\text { EBV-seropositive donor }\end{array}$ & - \\
\hline
\end{tabular}

\section{Monoclonal Antibodies (mAbs) and Flow Cytometry}

The mAbs Leu M1, Leu 12 and Leu 16 were purchased from Becton Dickinson (Sunnyvale, CA, USA), and the mAb Ki-1 was obtained from Dakopatts (Glostrup, Denmark).
Fluorescein isothiocyanate (FITC)- or phycoerythrin (PE)conjugated mouse IgG used as a control and PE-conjugated anti-mouse IgG as the second antibody were purchased from Dakopatts. The reactivity of cell lines with these antibodies was analyzed using flow cytometers (Cyto ACE-150, Nippon Bunko, Tokyo and FACSCalibur, Becton Dickinson).

\section{Stimulation with PMA}

TKS-1 and Raji cells (both $5 \times 10^{5} / \mathrm{ml}$ ) were resuspended in fresh culture medium containing $10 \mathrm{ng} / \mathrm{ml}$ of PMA. Twothirds of the medium was replaced every 2 days with fresh medium containing PMA for 7 days. Control cells were cultured in solvent medium. The expression of CD15, CD30, CD19, and CD20 was examined by staining the cells at 0,3 , 5 and 7 days after starting the experiment. TKS- 1 and Raji cell viability exceeded $80 \%$ throughout the experiments, which were performed in three flow cytometry studies.

\section{Western Blotting}

Cells were lysed in SDS sample buffer, fractionated by SDS-PAGE and then transferred to nitrocellulose membranes. Non-specific binding was blocked with 5\% nonfat milk and the membranes were incubated with appropriately diluted antibodies. The EBNA-1 and EBNA-2 proteins and LMP-1 were detected using serum from an individual who was EBV-seropositive, and the PE2 (DAKO, Denmark) and S12 mAbs, respectively. The membranes were then incubated with horseradish peroxidase-conjugated anti-mouse antibody and proteins were visualized using an enhanced chemiluminescence assay (GE Healthcare).

\section{Analysis of Promoter Usage for EBNA-1 in $\mathrm{CD}^{+}{ }^{+}$B Cells}

First-strand cDNA was synthesized from total RNA (5 $\mu \mathrm{g})$ extracted from each cell line using TRIzol (Invitrogen), oligo (dT) primers and the SuperScript III first strand synthesis system (Invitrogen) according to the manufacturer's instructions. We performed RT-PCR using the Cp-mRNA-specific primers, 5'-CATCTAAACCGACTGAAGAA-3' (sense) and 5'-CCC TGAAGGTGAACCGCTTA-3' (antisense); Wp-mRNAspecific primers, 5'-GTCCACACAAATCCTAG-3' (sense) and 5'-CCCTGAAGGTGAACCGCTTA-3' (antisense); Cp/Wp-EBNA1-specific primers, 5'-TGGCGTGTGACGTG GTGTAA-3' (sense) and 5'-CATTTCCAGGTCCTGTACC T-3' (antisense); Qp-EBNA1-specific primers, 5'-GTGCGC TACCGGATGGCG-3' (sense) and 5'-CATTTCCAGGTC CTGTACCT-3' (antisense); or the $18 \mathrm{~S}$ ribosomal RNAspecific primers 5'-TACATGCCGACGGGCGCTGACC-3' (sense) and 5'-CCTGCTGCCTTCCTTGGATG-3' (antisense). Transcripts were amplified using a GeneAmp PCR System 9700 thermocycler (Applied Biosystems, Foster City, CA) and Paq5000 DNA polymerase (Stratagene, La Jolla, CA, USA) in a total volume of $50 \mu 1$ for $30-35$ cycles, and the PCR products were analyzed by $2 \%$ agarose gel electrophoresis.

\section{Agarose Clonability Assays}

Cells (100 or 500) suspended in the top layer of $0.33 \%$ agar in RPMI 1640 containing 10\% FBS were poured onto a basal layer of $0.5 \%$ agar in RPMI 1640 containing $10 \%$ FBS in $35-\mathrm{mm}$ plates, and incubated at $37^{\circ} \mathrm{C}$ for 26 days. Colonies were counted under a microscope. 


\section{Cluster of differentiation positivity of subclones from TKS cells CD15 CD30 CD19

\begin{tabular}{llrc}
\hline Type 1 & $89.2(\%)$ & 91.8 & 97.7 \\
& $(113)$ & $(82)$ & $(109)$ \\
Type 2 & 98.5 & 95.2 & 4 \\
& $(221)$ & $(161)$ & $(\mathrm{N} / \mathrm{A})$
\end{tabular}

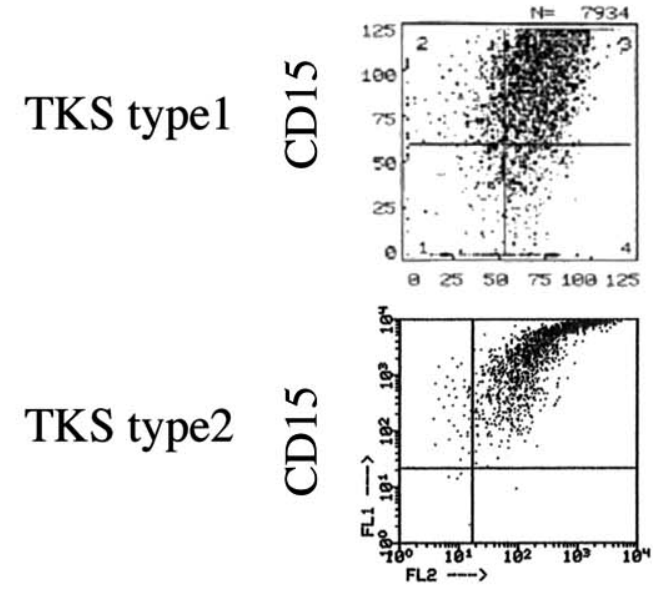

CD30
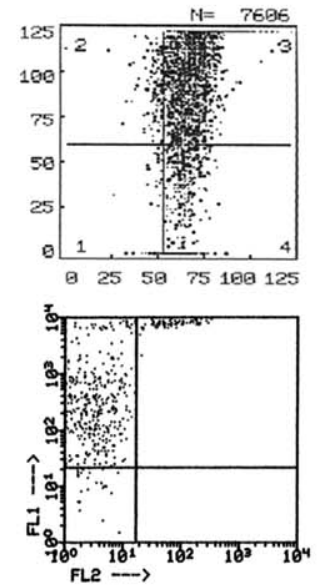

CD19

Fig. (1). Cluster of differentiation positivity of subclones from TKS cells. Two TKS subclones (type 1\&2) were isolated by repeated limiting dilution in 96-well micro-culture plates. The phenotypes of these clones were $\mathrm{CD} 15^{+} \mathrm{CD} 30^{+} \mathrm{CD} 19^{+} \mathrm{CD} 20^{+}$(type 1$)$ and $\mathrm{CD} 15^{+}$ $\mathrm{CD} 30^{+} \mathrm{CD} 19^{-} \mathrm{CD} 20^{+}$(type 2). Type 1 TKS subclone (TKS-1) reacted with following antibodies against surface antigens: Ig light chain kappa, HLA-DR, Leu 10, Leu 12 (CD19), Leu 16 (CD20), Leu M1 (CD15), and Ki-1 (CD30). These cells were unreactive to antibodies OKM1 (CD11b), Leu M2, Leu M3 (CD14), Leu M4, or to T cell surface or natural killer cell antigens. Numbers in parentheses are MFI values. Dot plots show representative flow cytometry data.

\section{RESULTS}

\section{Effects of PMA Stimulation on CD15 ${ }^{+}$B Cells}

We previously showed that TKS-1 cells express the two HL markers CD15 and CD30 [1]. Since a study has described a change in the expression of these HL markers in H-RS cells after stimulation with the tumour promoter phorbol-12- myristate-13-acetate (PMA) [24], we examined their expression in PMA-stimulated TKS-1 cells. Fig. (2) shows the changes in the ratios (\%) of TKS-1 or Raji cells that expressed CD15, CD30, CD19 or CD20 during PMA stimulation. Most TKS-1 cells remained CD $15^{+}$for 7 days after PMA stimulation. CD30 expression gradually declined, and less than $50 \%$ of the cells were positive by day 7 . CD19positive cells decreased rather quickly and only a few cells were positive by day 5 . In contrast, the expression of CD19, CD20, CD15, and CD30 in Raji cells did not significantly change, and most cells remained for CD19 and CD20 positive, and CD15 and CD30 negative. After more prolonged exposure to PMA, TKS-1 cells lost CD19 and
CD20 expression, but continued to express both CD15 and CD30 (data not shown). Figs. $(\mathbf{1}, \mathbf{2})$ shows representative dot plots of the flow cytometry data and mean fluorescence intensity (MFI) values.

\section{Analysis of EBV Gene Expression in TKS-1 Cells}

Three types of latent EBV infection with distinct profiles of viral gene expression are recognized in various EBVrelated tumours and cell lines. The type I latency found in $\mathrm{BL}$ and gastric carcinoma cells is characterized by the expression of EBV nuclear antigen 1 (EBNA1) as the sole EBV protein. Type II latency represented by HLs, T-cell lymphomas and nasopharyngeal carcinomas is characterized by the expression of EBNA1, latent membrane protein 1 (LMP1) and LMP2. The type III latency that occurs in LCLs established in vitro by EBV infection and lymphoproliferative disorder in immunocompromised hosts, is characterized by the expression of EBNA 1, 2, 3A, 3B and 3C, as well as LMPs 1, 2A and 2B, all of which are growth transformationassociated viral proteins. Messenger RNAs coding for 
TKS-1
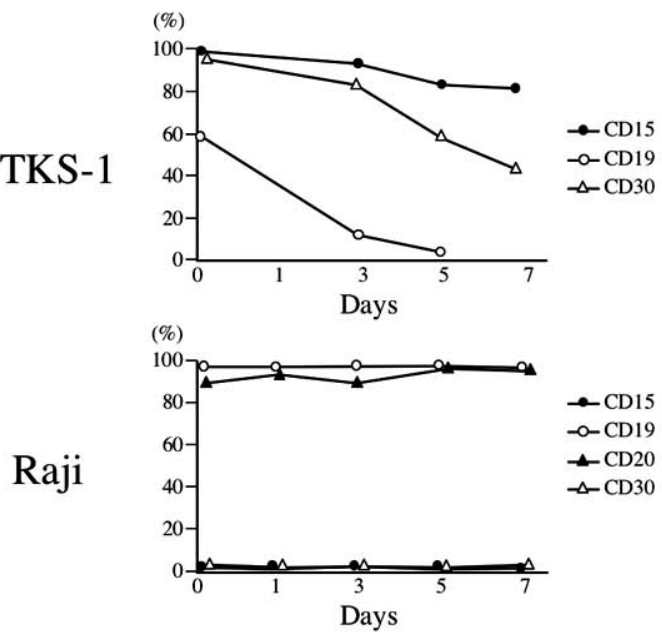

TKS-1 day0

CD15/30

15

$\frac{}{30}$

CD15/19
$\left.15\right|_{19}$
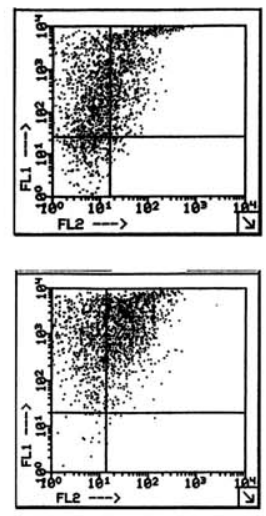

Raji

day0
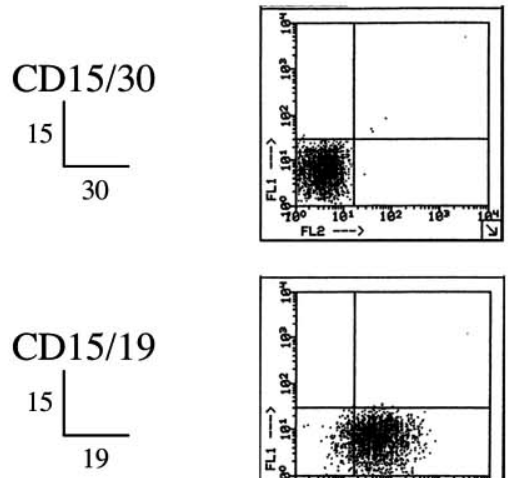
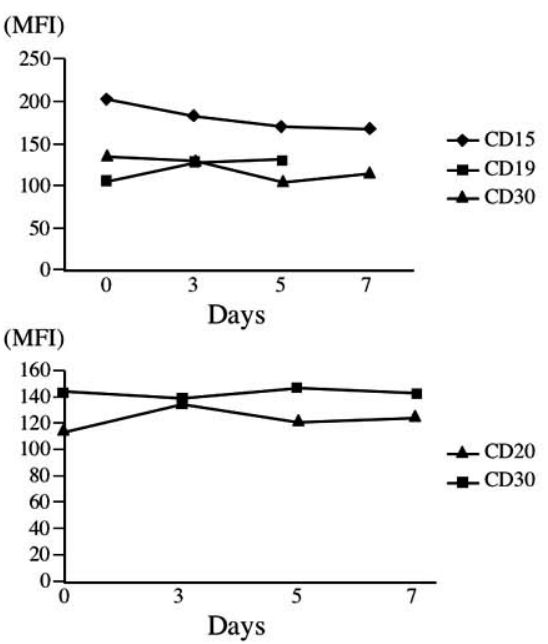

5
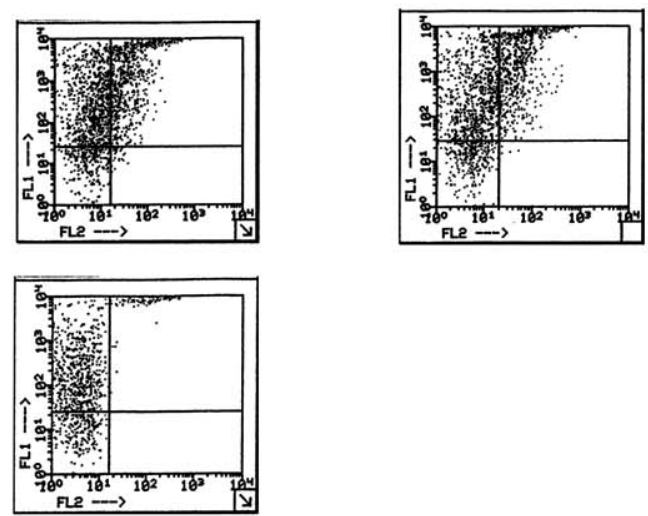

5
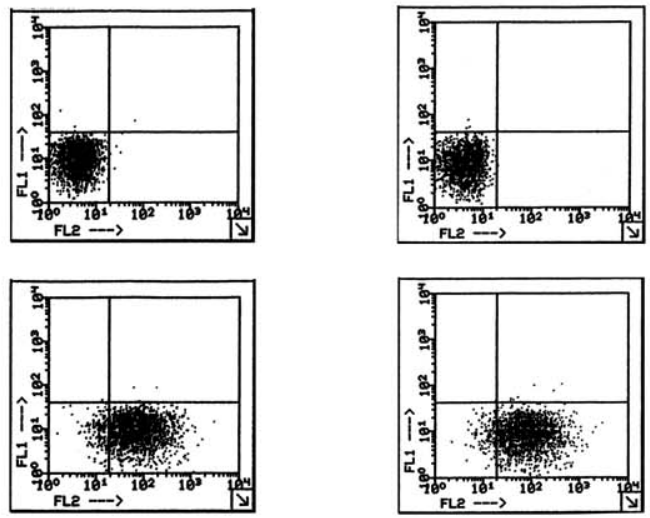

7
3
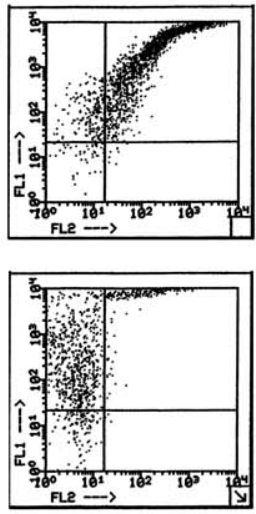

3
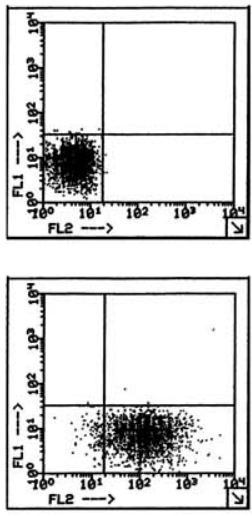

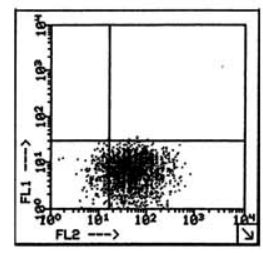

Fig. (2). Effects of PMA on surface makers of TKS-1 and Raji cells. TKS-1 and Raji cells ( $5 \times 10^{5} \mathrm{cells} / \mathrm{ml}$ each) were resuspended in fresh medium containing either $10 \mathrm{ng} / \mathrm{ml}$ PMA or solvent. Two-thirds of the medium was replaced with fresh medium every 2 days. Expression of CD15, CD30, CD19, and CD20 was examined by flow cytometry at $0,1,3,5,7$ days after starting the experiment. Data are representative of three repeated experiments. Dot plots show representative flow cytometry data.

EBNA1 as well as other EBNAs are transcribed from either of the $\mathrm{Cp}$ or Wp promoters of the virus in type III latency, whereas EBNA1 mRNA is transcribed from the Qp promoter in types I and II latency [25].
We examined EBV gene expression to determine the type of EBV latency in TKS-1 cells. Fig. (3) shows that TKS-1 and its subclones expressed EBNA1 and LMP1 at similar levels to those in EBV-positive LCLs established 


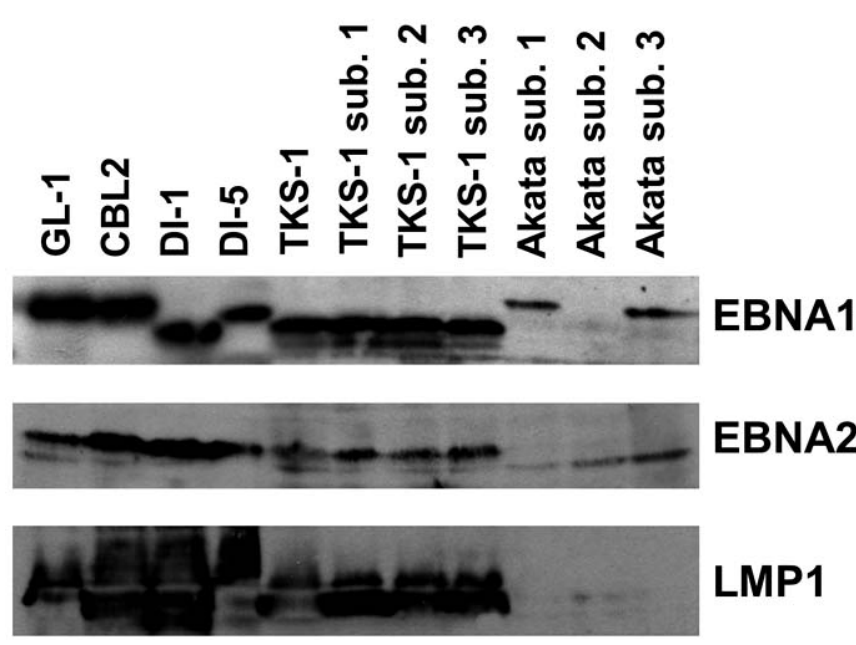

Fig. (3). Western blot analysis of EBV gene expression in the TKS-1 cells. Expression of EBNA1 (top panel), EBNA2 (middle panel), and LMP1 (bottom panel) was examined in cell lysates of TKS-1, three subclones (1-3) of TKS-1, three (1-3) subclones of Akata, GL-1, CBL2, DI-1, and DI- 5 by Western blotting as described in Materials and methods. Akata sublone 2 is an EBV clone that has lost EBV DNA and therefore does not express EBNA1.

from normal individuals. In contrast, less EBNA2 was expressed in TKS-1 and its subclones than in other LCLs. Only EBNA1 was expressed in Akata cells that were examined as a reference for type I latency.

RT-PCR Detection of Cp-mRNA, Wp-mRNA, Cp/WpDerived EBNA1, and Qp-Derived EBNA1 Transcripts

To determine which of the three possible EBNA promoters was used in TKS-1 cells and $\mathrm{RABM} / \mathrm{EBV}^{+} 1-3$ cell lines, we performed RT-PCR using the primer sets described in Materials and methods that distinguish mRNAs transcribed from $\mathrm{Cp}, \mathrm{Wp}$, and $\mathrm{Qp}$, as well as total RNA isolated from BJAB, Akata, LCL/B95-8 and TKS-1. Ribosomal RNA (18S) served as the internal control. The results shown in Fig. (4) indicate that Qp is used in TKS-1 cells similar to the Akata cell line with typical type I latency, but not in the EBV-transformed LCLs. Cp and Wp were used in the RABM/EBV ${ }^{+} 1-3$ cell lines and in regular LCLs, whereas Qp was not.

\section{Colony Formation by TKS-1 Cells in Soft Agar}

We performed agarose clonability assays to measure the anchorage-independent growth of TKS-1 cells, thus indicating their malignant potential. Either 100 or 500 cells from the TKS-1, typical LCLs, or Raji lines were seeded in soft agar and then colonies were counted. While none of the three typical LCLs established from normal individuals formed colonies, TKS-1 and Raji cells generated the same number of colonies (Fig. 5). These results indicate that TKS1 cells have higher malignant potential than typical LCLs.

\section{Ratio of CD15 Cells in $\mathrm{EBV}^{+}$B Cell Lines}

$\mathrm{RABM} / \mathrm{EBV}^{+} 1-3$ cell lines are $\mathrm{EBV}$-infected LCLs established by co-cultivating $\mathrm{CD}^{+}{ }^{+}$cells isolated from the bone marrow of a patient with RA and peripheral blood $\mathrm{B}$ lymphocytes obtained from an EBV-seronegative individual. HLA typing confirmed that these spontaneously established B cells were derived from a peripheral blood donor, and not from an RA patient. The reactivity of these cell lines with monoclonal antibodies was analyzed by flow cytometry and the calculated double positive ratio of $\mathrm{CD} 15^{+} / \mathrm{CD} 19^{+}$cells was 3.7, 27.3, 83.4 and $85.8 \%$ in $\mathrm{RABM} / \mathrm{EBV}^{+} 1$, B95-8 LCL, $\mathrm{RABM} / \mathrm{EBV}^{+} 2$ and $\mathrm{RABM} / \mathrm{EBV}^{+} 3$ cell lines, respectively (Table 1). In contrast, none of the regular LCLs established either spontaneously or by EBV infection in vitro expresses CD15.

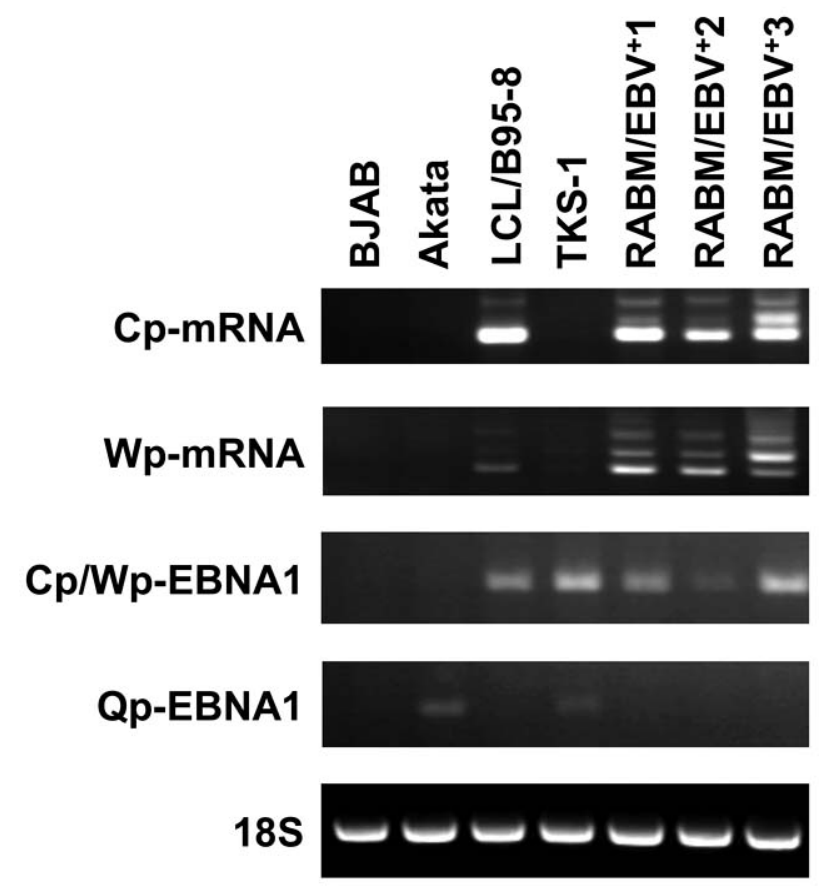

Fig. (4). RT-PCR analysis to detect Cp-mRNA, Wp-mRNA, Cp/Wp-derived EBNA1, and Qp-derived EBNA1 transcripts. RT-PCR proceeded using primer sets described in Materials and Methods. Total RNA was isolated from BJAB, Akata, LCL/B95-8, $\mathrm{RABM} / \mathrm{EBV}+1-3$ and TKS-1. Ribosomal RNA (18S) served as internal control.

\section{DISCUSSION}

This study demonstrated that TKS-1, an EBV-positive LCL cell line that was spontaneously established from a 
100 cells/dish

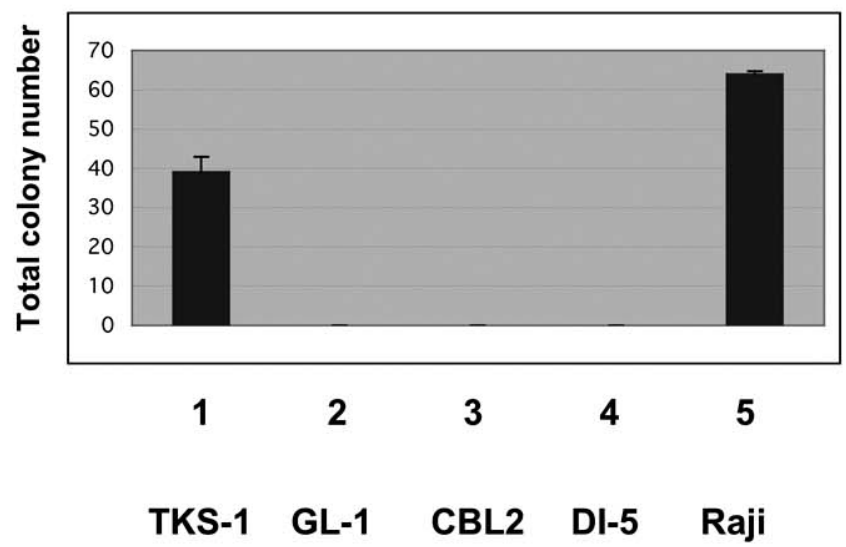

500 cells/dish

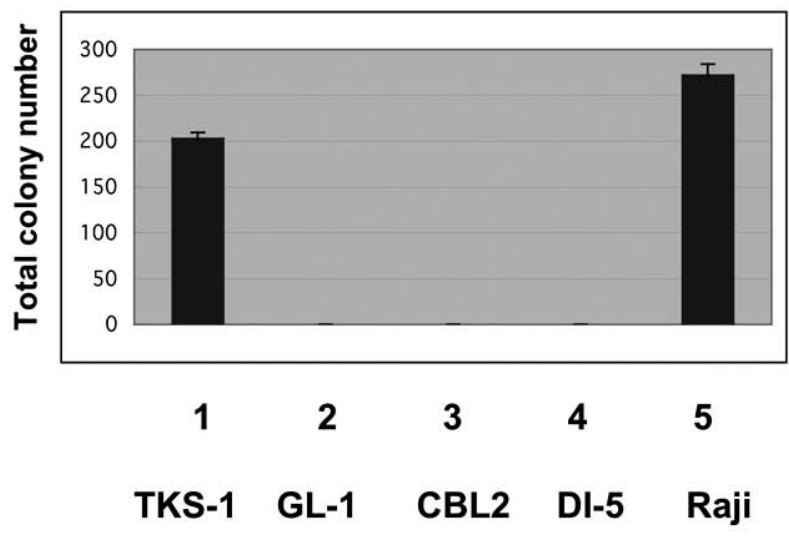

Fig. (5). Anchorage-independent growth of TKS-1 cells in soft agar. Either 100 (left panel) or 500 (right panel) TKS, GL-1, CBL2, DI-5 and Raji lines were seeded in soft agar and then colonies were counted 26 days later. Data represent means $\pm \mathrm{SEM}$.

patient with RA, expresses the HL markers CD15 and CD30 [26], and that PMA altered their expression to levels similar to those of H-RS cells. Hsu and Hsu examined the effect of PMA on the surface phenotype of H-RS cells obtained from the spleens of patients with HL and showed that CD15 expression persisted for at least three days, whereas that of CD30 gradually declined [24]. TKS-1 cells remained CD15 positive for 5 days, and then this condition persisted after PMA stimulation. In contrast, the expression of CD30 gradually decreased after adding TPA. CD19 expression was rapidly lost and remained almost undetectable after 3 days of PMA stimulation. Hsu and Hsu studied H-RS cells only at 3 days after starting PMA stimulation [24]. Therefore, the present data from TKS-1 cells cannot be precisely compared with those from H-RS cells. TKS-1 and H-RS cells both retain CD15 expression while gradually losing CD30 after PMA stimulation. In addition to TKS-1, RABM/EBV ${ }^{+} 1-3$ cells obtained by co-cultivating $\mathrm{CD} 34^{+}$cells isolated from the bone marrow of a patient with RA and B lymphocytes obtained from healthy individuals also expressed CD15. Since the origin of $\mathrm{RABM} / \mathrm{EBV}^{+}$cells are $\mathrm{B}$ lymphocytes obtained from EBV-seronegative individuals, the bone marrow $\mathrm{CD}^{+} 4^{+}$cell preparation probably contained EBV, which transformed cocultivated B cells from a seronegative individual. Together with the results of the TKS-1 cells, this finding suggests that EBV strains harbored by patients with RA tend to induce $\mathrm{CD} 15$ expression. We determined that $\mathrm{RABM} / \mathrm{EBV}^{+} 1-3$ cell lines used $\mathrm{Cp}$ and $\mathrm{Wp}$, but not $\mathrm{Qp}$.

TKS-1 cells express EBNA1, EBNA2, and LMP1 and in this sense can be categorized as latency III. However, low EBNA2 expression and usage of the Op promoter for EBNA1 mRNA differ from those in regular LCLs and resemble the latency II type of H-RS cells in HL [27]. Thus we speculate that TKS-1 cells are intermediate between latency II and latency III with respect to EBV gene expression. In terms of malignant potential assessed by anchorage independent growth, TKS-1 cells clearly differed from regular LCLs established from normal individuals. While typical LCLs generated hardly any colonies in soft agar medium, TKS-1 cells produced as many colonies as the BL Raji cells. Thus the malignant potential of TKS is much greater than that of regular LCLs and as high as that of Raji cells. To determine whether MTX affects EBV latency expression and malignancy, and whether CD15 plays any role in the growth of TKS-1 cells in soft agar would be of interest. These issues are under investigation.

Svensson et al. have identified reversible $\mathrm{EBV}^{-}$ lymphadenopathy and bone marrow involved with HL in a single patient RA treated with MTX [28]. They suggest that most reported MTX-induced lymphomas have a background of RA, which itself confers an increased risk for the development of lymphoproliferative disorders. MTX-induced lymphoma in RA patients might not represent a distinct clinical entity, but rather reflect an increased risk of developing lymphoma that is inherent in this patient group [28]. Mariette et al. have performed a nationwide prospective study that suggests an increased risk for HL [4], but not for NHL, in RA patients treated with MTX. Furthermore, they concluded that the overall risk of NHL is not increased in RA treated with MTX. These MTX-related NHLs are resolved simply by drug withdrawal, whereas HL is often associated with EBV, refractory to MTX withdrawal, and requires chemoradiotherapy. This indicates that HL associated with RA has higher malignant potential $[4,29]$. In fact, a large population-based case-control study has shown that a statistically significant increased risk of $\mathrm{HL}$ is associated with a history of several autoimmune conditions, including RA. Miyazaki et al. examined the latency pattern of EBV and found that 2 of 9 patients who achieved a complete response had latency type III. Another whose disease stabilized had latency type II. The former two went into remission after MTX withdrawal especially in NHL with latency type III infection. Miyazaki et al. thus suggested that analysis of EBV infection, including latency types, is useful to decide optimal therapeutic strategies [30].

In conclusion, the results presented herein suggest that CD15+ EBV-infected LCLs from patients with RA tend to acquire properties that differ from those of regular LCLs and are similar to those of H-RS cells of HL. These findings may provide an insight into the mechanism of development of HL in patients with RA. 


\section{ACKNOWLEDGEMENTS}

The excellent technical support of Ms. I. Takeshita (Division of Hematology and Rheumatology, Department of Medicine, Nihon University, School of Medicine) is acknowledged. The authors declare they have no conflict of interest. This work was supported by a Nihon University Clinical Research Grant.

\section{REFERENCES}

[1] Takei M, Kang H, Tomura K, et al. Expression of Leu M1 antigen on a monoclonal $\mathrm{B}$ cell line established from a patient with rheumatoid arthritis. Immunol Lett 1989; 23: 43-7.

[2] Kono H, Inokuma S, Matsuzaki Y, et al. Two cases of methotrexate induced lymphomas in rheumatoid arthritis: an association with increased serum IgE. J Rheumatol 1999; 26: 2249-53.

[3] Kamel OW, van de Rijn M, Weiss LM, et al. Brief report: reversible lymphomas associated with Epstein-Barr virus occurring during methotrexate therapy for rheumatoid arthritis and dermatomyositis. $\mathrm{N}$ Engl J Med 1993; 328: 1317-21.

[4] Mariette X, Cazals-Hatem D, Warszawki J, et al. Lymphomas in rheumatoid arthritis patients treated with methotrexate: A 3-year prospective study in France. Blood 2002; 99: 3909-15.

[5] Baecklund E, Iliadou A, Askling J, et al. Association of chronic inflammation, not its treatment, with increased lymphoma risk in rheumatoid arthritis. Arthritis Rheum 2006; 54: 692-701.

[6] von Wasielewski R, Mengel M, Fischer R, et al. Classical Hodgkin's disease. Clinical impact of the immunophenotype. Am J Pathol 1997; 151: 1123-30.

[7] Hanjan SN, Kearney JF, Cooper MD. A monoclonal antibody (MMA) that identifies a differentiation antigen on human myelomonocytic cells. Clin Immunol Immunopathol 1982; 23: 17288.

[8] Huang LC, Brockhaus M, Magnani JL, et al. Many monoclonal antibodies with an apparent specificity for certain lung cancers are directed against a sugar sequence found in lacto-N-fucopentaose III. Arch Biochem Biophys 1983; 220: 318-20.

[9] Huang LC, Civin CI, Magnani JL, Shaper JH, Ginsburg V. My-1, the human myeloid-specific antigen detected by mouse monoclonal antibodies, is a sugar sequence found in lacto-N-fucopentaose III. Blood 1983; 61: 1020-3.

[10] Larsen E, Palabrica T, Sajer S, et al. PADGEM-dependent adhesion of platelets to monocytes and neutrophils is mediated by a lineagespecific carbohydrate, LNF III (CD15). Cell 1990; 63: 467-74.

[11] Stenberg PE, McEver RP, Shuman MA, Jacques YV, Bainton DF. A platelet alpha-granule membrane protein (GMP-140) is expressed on the plasma membrane after activation. J Cell Biol 1985; 101: 880-6.

[12] Alspaugh MA, Jensen FC, Rabin H, Tan EM. Lymphocyte transformed by Epstein-Barr virus. induction of nuclear antigen reactive with antibody in rheumatoid arthritis. J Exp Med 1978; 147: 1018-27.

[13] Tosato G, Steinberg AD, Yarchoan R, et al. Abnormally elevated frequency of Epstein-Barr virus- infected B cells in the blood of patients with rheumatoid arthritis. J Clin Invest 1984; 73: 1789-95.

[14] Fox R, Sportman R, Rhodes G, Luka J, Peason G, Vaughan J. Rheumatoid arthritis synovial membrane contains a 62000molecular-weight protein that shares an antigenic epitope with the Epstein-Barr virus-encoded associated nuclear antigen. J Clin Invest 1986; 77: 1539-47.

[15] Takei M, Mitamura K, Fujiwara S, et al. Detection of Epstein-Barr virus-encoded small RNA 1 and latent membrane protein 1 in synovial lining cells from rheumatoid arthritis patients. Int Immunol 1997; 9: 739-43.

[16] Edinger JW, Bonneville M, Scotet E, Houssaint E, Schumacher HR, Posnett DN. EBV gene expression not altered in rheumatoid synovia despite the presence of EBV antigen-specific $\mathrm{T}$ cell clones. J Immunol 1999; 162: 3694-701.

[17] Saal JG, Krimmel M, Steidle M, et al. Synovial Epstein-Barr virus infection increases the risk of rheumatoid arthritis in individuals with the shared HLA-DR4 epitope. Arthritis Rheum 1999; 42: 1485-96.

[18] Blaschke S, Schwarz G, Moneke D, Binder L, Müller G, Reuss-Borst M. Epstein-Barr virus infection in peripheral blood mononuclear cells, synovial fluid cells, and synovial membranes of patients with rheumatoid arthritis. J Rheumatol 2000; 27: 866-73.

[19] Takeda T, Mizugaki Y, Matsubara L, Imai S, Koike T, Takada K. Lytic Epstein-Barr virus infection in the synovial tissue of patients with rheumatoid arthritis. Arthritis Rheum 2000; 43: 1218-25.

[20] Mehraein Y, Lennerz C, Ehlhardt S, Remberger K, Ojak A, Zang KD. Latent Epstein-Barr virus (EBV) infection and cytomegalovirus (CMV) infection in synovial tissue of autoimmune chronic arthritis determined by RNA- and DNA-in situ hybridization. Mod Pathol 2004; 17: 781-9.

[21] Takei M, Ishiwata T, Mitamura K, et al. Decreased expression of signaling lymphocytic-activation molecule-associated protein (SAP) transcripts in $\mathrm{T}$ cells from patients with rheumatoid arthritis. Int Immunol 2001; 13: 559-65.

[22] Hirohata S, Yanagida T, Nakamura H, Yoshino S, Tomita T, Ochi T. Bone marrow CD34+ progenitor cells from rheumatoid arthritis patients support spontaneous transformation of peripheral blood $\mathrm{B}$ cells from healthy individuals. Rheumatol Int 2000; 19: 153-9.

[23] Menezes J, Leibold W, Klein G, Clements G. Establishment and characterization of an Epstein-Barr virus (EBC)-negative lymphoblastoid B cell line (BJA-B) from an exceptional, EBVgenome-negative African Burkitt's lymphoma. Biomedicine 1975; 22: $276-84$

[24] Hsu SM, Hsu PL. Phenotypes and phorbol ester-induced differentiation of human histiocytic lymphoma cell lines (U-937 and SU-DHL-1) and Reed-Sternberg cells. Am J Pathol 1986; 122: $223-$ 30 .

[25] Szekely L, Chen F, Teramoto N, et al. Restricted expression of Epstein-Barr virus (EBV)-encoded, growth transformation-associated antigens in an EBV- and human herpesvirus type 8-carrying body cavity lymphoma line. J Gen Virol 1998; 79: 1445-52.

[26] Chang HW, Chong SM, Peh, SC, Lee SH. X-chromosome inactivation analysis of isolated Reed-Sternberg cells in nodular sclerosing Hodgkin's disease. Br J Haematol 1999; 107: 641-7.

[27] Marshall NA, Culligan DJ, Johnston PW, Millar C, Barker RN, Vickers MA. CD4 (+) T-cell responses to Epstein-Barr virus (EBV) latent membrane protein 1 in infectious mononucleosis and EBVassociated non-Hodgkin lymphoma: Th1 in active disease but $\operatorname{Tr} 1$ in remission. Br J Haematol 2007; 139: 81-9.

[28] Svensson AM, Jacobson ER, Ospina D, Tindle BH. Reversible Epstein-Barr virus-negative lymphadenopathy and bone marrow involved by Hodgkin's lymphoma in a rheumatoid arthritis patient undergoing long-term treatment with low-dose methotrexate: A case report and review of the literature. Int J Hematol 2006; 88: 47-50.

[29] Landgren O, Engels EA, Pfeiffer RM, et al. Autoimmunity and susceptibility to Hodgkin lymphoma: A population based case control study in Scandinavia. J Natl Cancer Inst 2006; 98: 1321-30.

[30] Miyazaki T, Fujimaki K, Shirasugi Y, et al. Remission of lymphoma after withdrawal of methotrexate in rheumatoid arthritis: Relationship with type of latent Epstein-Barr virus infection. Am J Hematol 2007; 82: $1106-9$ 